\title{
Psychological distress and mental health of Thai caregivers
}

\author{
Vasoontara Yiengprugsawan ${ }^{1 *}$ Sam-ang Seubsman² and Adrian C Sleigh ${ }^{1}$
}

\author{
* Correspondence: vasoontara. \\ yieng@gmail.com \\ ${ }^{1}$ National Centre for Epidemiology \\ and Population Health, The \\ Australian National University, \\ Canberra, Australia \\ Full list of author information is \\ available at the end of the article
}

\begin{abstract}
Background: As the proportion of elderly people within a population increases there is an accompanying increase in the role of informal caregivers. Many studies on caregivers report negative health outcomes but very few have addressed positive aspects of caregiving. This study examines characteristics of Thai caregivers, the distribution of psychological distress and mental health among caregivers, and the association between caregiver status and psychological distress.

Methods: This report is based on an ongoing national cohort study of 60,569 Thai adults. Caregiving was common in the cohort, and in $20096.6 \%$ were full-time and $27.5 \%$ were part-time caregivers. Outcomes of the study were reported using an international standard Kessler 6 for psychological distress and a national Thai Mental Health Indicator. Determinants included age, sex, marital status, household income, work status and urban-rural residence. Frequency of social contacts was also included as an explanatory variable.
\end{abstract}

Results: Among cohort members, 27.5\% were part-time caregivers and 6.6\% were full-time caregivers. Compared to non-caregivers, full-time caregivers tended to be older, to be married, to be in the lowest household income group, to be unpaid family members, and to reside in rural areas. We noted the seeming contradiction that when compared to non-caregivers, the caregivers reported higher psychological distress but higher positive mental health (i.e., self-esteem and content with life), higher positive mental capacity (i.e., coping with crises), and higher positive mental quality (i.e., helping others).

After adjusting for possible covariates, part-time and full-time caregivers were more likely to report high psychological distress (Adjusted Odds Ratios, AOR 1.33 and 1.78 among males and 1.32 and 1.45 among females). Less contact with colleagues was associated with high psychological distress both in males and females (AOR 1.36 and 1.33). Less contact with friends was also associated with high psychological distress, especially among females (AOR 1.27 and 1.42).

Conclusions: This study highlights caregivers in Thailand, the strong possibility of mental health benefits, some risks of associated psychological distress, and the positive role of keeping social contacts. Early identification of vulnerable caregivers is required to target effective health promotion.

Keywords: Caregivers, Psychological distress, Mental health, Cohort study, Thailand

\section{Springer}

(c) 2012 Yiengprugsawan et al.; licensee Springer. This is an Open Access article distributed under the terms of the Creative Commons Attribution License (http://creativecommons.org/licenses/by/2.0), which permits unrestricted use, distribution, and reproduction in any medium, provided the original work is properly cited. 


\section{Introduction}

The developed world's population is aging due to increased life expectancies and decreased fertility rates. Increase of the aged population has been accompanied by an increased demand on the family as well as the health care system and long-term care services (Hussein and Manthorpe 2005). Caregiving can be overwhelming for caregivers both physically and psychologically (Brown 2007; Savage and Bailey 2004; Treasure 2004; Vitaliano et al. 2003).

Although negative outcomes for caregivers are commonly reported, a limited number of studies acknowledge positive outcomes for caregivers (Baronet 2003; Cohen et al. 2002; Koerner et al. 2009; Yamamoto-Mitani et al. 2004). For example, caregivers can show their affection and perceive social honour when caring for loved ones. Caregiving can be rewarding and can make a positive contribution to caregivers' lives, hence providing satisfaction in life (Kuuppelomaki et al. 2004; Ribeiro and Paul 2008). Interestingly, in contrast to the general belief, one study has shown that almost half of caregivers derive positive utility from caregiving tasks, hence their happiness would decline if the tasks had to be passed on to others (Brouwer et al. 2005).

Recent studies have found that caregivers fear social isolation and their life satisfaction can be correlated with their ability to access social networks and support from peers (Guerra et al. 2008; Stoltz et al. 2004). One study has found that the influence of socio-emotional support on caregiver feelings of gain is complex and will vary depending on its source i.e. family members and friends (Shirai et al. 2009). Another study has shown difficulty arranging assistance from friends correlated significantly with caregiver burden and depression (Chang et al. 2001). Social support at the work place, from supervisors and colleagues, were also shown to be protective against adverse mental health outcomes (Sinokki et al. 2009).

Previous studies have found a relationship between gender and the impact of caregiving (Godfrey and Warshaw 2009; Singleton 2000). Many caregivers, typically females in their $40 \mathrm{~s}$ and 50s, have had difficulties balancing their family roles and job responsibilities (Singleton 2000). One study reported a gender differential in self-silence on caring for different reasons and subsequent consequences for mental health. For example, some men maintain a positive front as a means of coping (Ussher and Perz 2010).

There have been limited studies on caregivers in Asia and most were done in higher income countries. This includes a study in Hong Kong which reported adverse physical and psychological health and poorer quality of life among caregivers (Ho et al. 2009). A study in Taiwan has found quality of life of caregivers varies according to their job satisfaction and family support (Chou et al. 2010). A study of Japanese family caregivers has drawn attention to both positive and negative impacts on quality of life of caregivers (Yamamoto-Mitani et al. 2004). A cross-cultural comparative study of caregivers has observed differences between Western and Eastern cultures in the role of social support, where Western caregivers use more formal support and Asian caregivers commonly rely on extended family support (Kong 2007). Although many East Asian countries have addressed the issue of population ageing and caregiver burden, there have been relatively fewer studies done in Southeast Asia.

To address gaps in the current literature on caregivers in emerging economies, this study investigates caregivers among a large national cohort of Thai adults. Caregivers in this study refers to informal carers who provide unpaid care to sick or disabled family members, which would include both physical and mental disability as well as sickness, 
frailty or dependence due to older age. This report examines socio-demographic attributes of part-time and full-time caregivers and distribution of psychological distress and mental health among caregivers. We then investigate the association between caregiver status and psychological distress taking into account the role of social contacts and other potential covariates. Both positive and negative aspects are investigated to provide information on risks and protective factors associated with caregiving.

\section{Methods}

\section{The Thai Cohort Study}

The Thai Health-Risk Transition Project includes an ongoing Thai Cohort Study (TCS) of 87,134 adult Open University students residing throughout the country. The cohort is made up of distance-learning students who were enrolled at Sukhothai Thammathirat Open University (STOU) in 2005. The cohort members represent the Thai population well in terms of sex ratio, median age, religion, regional distribution, and median income (Sleigh et al. 2008). A 4-year follow-up was conducted in 2009 $(n=60569$, response rate $70 \%)$ with questions on socio-demographic characteristics, physical health, mental health and wellbeing, injury, and caregiver status. For this report, we analysed the 2009 cohort follow-up data.

\section{Measures and definitions}

Characteristics of cohort members examined here were age (3 categories), sex, marital status (3 categories), household monthly income in Baht (4 categories), work status (4 categories); and geographical residence (rural and urban areas). Health-risk behaviours such as alcohol drinking and smoking also were included in the analysis. Outcomes measured included an international standard measure for psychological distress, Kessler-6, and a national Thai Mental Health Indicator.

Caregiver in this study refers to informal carers who provide unpaid care to family members. Caregiver status was ascertained by asking: "Do your regularly care for a sick or disabled family member? ('no,' yes - a part-time caregiver,' or 'yes - a full-time caregiver')"

Psychological distress was measured using the standard Kessler 6 instrument which included the following questions "In the past 4 weeks, how often did you feel: 1) so sad nothing could cheer you up, 2) nervous, 3) restless or fidgety, 4) hopeless, 5) everything was an effort, 6) worthless?" Responses were scored from 0 to 4 ('none,', little,'some,' 'most', or 'all the time') (Kessler et al. 2003). Scores for the six questions were then totaled and those scoring 13 or higher were dichotomized into having 'high psychological distress'; these are consistent with relevant recent Asian literature (Fushimi et al. 2011; Hozawa et al. 2009). All the questions were translated into Thai by a professional public health team and were validated with pilot subjects. As well, the Kessler psychological distress questions have also been used in another Thai study (Songprakun and McCann 2012).

Mental health was measured using the Thai Mental Health Indicator (TMHI) developed by the Department of Mental Health within the Ministry of Public Health (Mongkol et al. 2001; Songprakun and McCann 2012; Mongkol et al. (2007). The 15-item short version of the TMHI included: positive mental state ('self-esteem', 'content with life,' 'relaxed'), negative mental state ('bored,' 'disappointed,' 'life full of miseries'), mental capacity ('can face problems', 'can control emotions', 'confident in facing crises'), 
mental quality ('sympathetic towards others', 'help others when have a chance,' 'happy in helping others'), and social support ('feel secure with family, 'trust family will take care of when ill,' 'family loves and care for each other'). Responses were 'never,' 'a little,'a lot', and 'very much'.

Social contacts were also assessed with a question: "How frequently do you spend time doing each of the following activities? Spend time socially with... 1) colleagues; 2) friends not connected to work; 3) neighbours." Responses were: 'every week', 'once or twice per month', and 'rarely or never'.

\section{Data analyses and model selection}

Data scanning and editing used Thai Scandevet software. Further data editing was completed using SQL and SPSS software and for analysis we used Stata version 11. For multivariate logistic regression of the effect of caregiving on psychological distress (dichotomised into 'high' vs 'not high'), we report Adjusted Odds Ratios (AOR) and 95\% Confidence Intervals. Other studies have found differences in health outcomes and needs among male and female caregivers (Godfrey and Warshaw 2009; Ussher and Perz 2010). Our preliminary analyses showed that females were more likely to report AOR 1.38 [95\% CI 1.25-1.51]. Final analyses were reported separately by sex.

Covariates for psychological distress were chosen based on experience with risk factors of adverse health outcomes in the Thai Cohort Study (Tawatsupa et al. 2010; Yiengprugsawan et al. 2011). Thai Mental Health Indicators and sociodemographic associations among Thai cohort members were described elsewhere (Yiengprugsawan et al. 2011).

\section{Ethical issues}

Ethics approval was obtained from Sukhothai Thammathirat Open University Research and Development Institute (protocol 0522/10) and the Australian National University Human Research Ethics Committee (protocol 2004/344 and 2009/570 for follow-up). Informed written consent was obtained from all participants.

\section{Results}

Among cohort members, 27.5\% reported being part-time caregivers and 6.6\% reported being full-time caregivers (Table 1). Compared to non-caregivers, full-time caregivers tended to be older (26.9\% vs $43.5 \%$ aged 40 and older) and were more likely to be married $(54.0 \%$ vs $65.6 \%)$. Full-time caregivers were more likely to be in the lowest household income group $(<10,000$ Baht per month), more likely to report their work status as being an unpaid family member, and more likely to reside in rural areas. Health risk behaviours of engaging in smoking and drinking were slightly more common among caregivers. Social contacts with colleagues and neighbours were quite similar among caregiver categories except for reporting 'never or rarely' socialising with friends (71.3\% vs $66.2 \%$ vs $62.8 \%$ among non-, part- and full-time caregivers, respectively).

Psychological distress was compared by caregiver status. Across all Kessler-6 statements, there was a clear gradient of increasing distress for non-, part-, and full-time caregivers $(4.2 \%$ vs $4.8 \%$ vs $6.2 \%$ among males and $5.7 \%$ vs $7.3 \%$ vs $8.5 \%$ among females) (Table 2). 
Table 1 Characteristics of cohort members by caregiver status, Thai Cohort Study 2009

\begin{tabular}{|c|c|c|c|c|}
\hline \multirow[t]{2}{*}{ Cohort characteristics $N=60,569$} & \multirow[t]{2}{*}{ Overall } & \multicolumn{3}{|c|}{ Caregiver status (column \%) } \\
\hline & & $\begin{array}{l}\text { Non-caregiver } \\
65.9 \%\end{array}$ & $\begin{array}{l}\text { Part-time } \\
\text { caregiver } 27.5 \%\end{array}$ & $\begin{array}{l}\text { Full-time } \\
\text { caregiver } 6.6 \%\end{array}$ \\
\hline \multicolumn{5}{|l|}{ Demographic characteristics } \\
\hline \multicolumn{5}{|l|}{ Sex } \\
\hline Male & 45.3 & 43.8 & 47.5 & 48.4 \\
\hline Female & 54.8 & 56.2 & 52.5 & 51.6 \\
\hline \multicolumn{5}{|l|}{ Age (year) } \\
\hline $20-29$ & 27.4 & 29.7 & 24.5 & 18.0 \\
\hline $30-39$ & 42.6 & 43.4 & 41.6 & 38.5 \\
\hline $40+$ & 30.0 & 26.9 & 33.9 & 43.5 \\
\hline \multicolumn{5}{|l|}{ Marital status } \\
\hline Married & 55.3 & 54.0 & 55.8 & 65.6 \\
\hline Never married & 37.9 & 39.3 & 34.5 & 26.1 \\
\hline Separated, divorced, widowed & 6.8 & 6.7 & 6.7 & 8.3 \\
\hline \multicolumn{5}{|l|}{ Socio-geographic characteristics } \\
\hline \multicolumn{5}{|l|}{ Household monthly income (Baht) * } \\
\hline$<10,000$ & 18.8 & 17.9 & 20.2 & 20.8 \\
\hline $10,000-19,999$ & 22.4 & 23.4 & 21.0 & 18.9 \\
\hline $20,000-30,000$ & 35.7 & 36.3 & 35.1 & 33.3 \\
\hline$>30,000$ & 23.1 & 22.5 & 23.8 & 27.0 \\
\hline \multicolumn{5}{|l|}{ Work status } \\
\hline Doing paid work & 73.2 & 74.9 & 71.1 & 66.5 \\
\hline Unpaid family workers & 7.3 & 6.6 & 7.9 & 11.4 \\
\hline Seeking work & 2.2 & 2.1 & 2.3 & 2.6 \\
\hline Others & 17.3 & 16.3 & 18.7 & 19.5 \\
\hline \multicolumn{5}{|l|}{ Geographical residence } \\
\hline Rural residence & 44.0 & 41.4 & 48.2 & 51.7 \\
\hline Urban residence & 56.0 & 58.6 & 51.9 & 48.3 \\
\hline \multicolumn{5}{|l|}{ Health covariates } \\
\hline Regular smokers - yes & 7.7 & 7.3 & 8.4 & 8.0 \\
\hline Regular alcohol drinkers - yes & 13.7 & 13.0 & 14.2 & 15.5 \\
\hline \multicolumn{5}{|l|}{ Social contacts } \\
\hline \multicolumn{5}{|l|}{ Colleagues: } \\
\hline Every week & 21.3 & 20.4 & 23.0 & 22.4 \\
\hline Once or twice per month & 22.6 & 22.4 & 23.8 & 19.5 \\
\hline Rarely or never & 56.2 & 57.2 & 53.2 & 58.1 \\
\hline \multicolumn{5}{|l|}{ Neighbours: } \\
\hline Every week & 8.9 & 8.8 & 9.3 & 9.4 \\
\hline Once or twice per month & 14.1 & 14.0 & 14.7 & 13.0 \\
\hline Rarely or never & 77.0 & 77.3 & 76.1 & 77.7 \\
\hline \multicolumn{5}{|l|}{ Friends: } \\
\hline Every week & 16.2 & 15.0 & 17.8 & 20.8 \\
\hline Once or twice per month & 14.5 & 13.7 & 16.0 & 16.4 \\
\hline Rarely or never & 69.3 & 71.3 & 66.2 & 62.8 \\
\hline
\end{tabular}

*1 \$US 35 Thai Baht. 
The Thai Mental Health Indicator was analysed in relation to caregiver status (Table 3). Caregivers were more likely to report a higher positive mental state ('self-esteem,' 'content with life', and 'relaxed') and less likely to report a lower negative mental state ('life is full of miseries') for both males and females. Caregivers were also more likely to report higher mental capacity ('can control emotions' and 'confident in facing crises' among males) and higher mental quality ('sympathetic toward others', 'help others when have a chance,' 'happy in helping out others' among females). Male caregivers were more likely to report higher social support than non caregivers ('feel secure when stay with family' and 'family members love and care for each other'). But no such trend was observed among females.

Multivariate logistic regression was used to analyse associations between caregiver status and psychological distress based on overall Kessler-6 summary scores, adjusting for covariates (Table 4). After adjusting for possible covariates, part-time and full-time caregivers were more likely to report high psychological distress. Adjusted Odds Ratios were 1.33 [95\% CI 1.20-1.49] and 1.78 [95\% CI 1.49-2.13] among males and 1.32 [95\% CI 1.20-1.44] and 1.45 among females [95\% CI 1.24-1.70]. The role of social contacts was also examined as a predictor of high psychological distress. Having contact with colleagues 'rarely or never' was associated with high psychological distress both in males and females; AOR were 1.36 [95\% CI 1.19-1.95] and 1.33 [95\% CI 1.19-1.49]. Reporting contact with friends 'rarely or never' was also associated with high psychological distress, especially among females. Cohort members of younger age, who were separated, divorced or widowed, with lower income, or seeking work were all more likely to report psychological distress. Being a female smoker was also highly associated with having psychological distress.

\section{Discussion}

Our study adds to the growing body of literature examining both the positive and negative aspects of caregiving and it is one of the first large studies of caregiving in middle-income Asia. We used both the international standard measure of psychological distress (Kessler6) and a national measure, the Thai Mental Health Indicator (TMHI). There was a clear gradient of part-time and full-time caregivers experiencing more psychological distress.

We noted the seeming contradiction that when compared to non-caregivers, the caregivers reported higher psychological distress but higher positive mental health (i.e., self-esteem and content with life), higher positive mental capacity (i.e., coping with crises), and higher positive mental quality (i.e., helping others). The high distress could be explained by the daily activities which could put pressure on caregivers physically and psychologically (Brown 2007; Savage and Bailey 2004; Treasure 2004; Vitaliano et al. 2003). However, taking on the task of caregiving can also be positive for mental health when helping others and managing crises. These findings also confirm other studies on the positive role of caregiving on self-esteem and sense of life satisfaction (Kuuppelomaki et al. 2004; Ribeiro and Paul 2008.

On multivariate analysis of caregiving and psychological distress, we found significant associations with a dose-response effect: full-time caregivers were worse off than parttime caregivers who in turn were more distressed than non-caregivers. This is especially so among males. We also noted that lack of social contacts (colleagues and friends) significantly contributed to this psychological distress. We could not assess the association for family members as 'high contact' could be confused with the caregiving task itself. 
Table 2 Psychological distress and caregiver status by age and sex, Thai Cohort Study 2009

\begin{tabular}{|c|c|c|c|c|c|c|}
\hline \multirow{3}{*}{$\begin{array}{l}\text { Kessler- } 6 \text { psychological distress } \\
N=60,569\end{array}$} & \multicolumn{6}{|c|}{ Column (\%) by caregiver status } \\
\hline & \multicolumn{3}{|c|}{ Males } & \multicolumn{3}{|c|}{ Females } \\
\hline & Non & Part-time & Full-time & Non & Part-time & $\overline{\text { Full-time }}$ \\
\hline \multicolumn{7}{|c|}{ Kessler 6 items (reported 'all' or 'most of the time') } \\
\hline Worthless & 1.1 & 1.2 & 1.7 & 1.7 & 1.8 & 2.5 \\
\hline Hopeless & 1.3 & 1.6 & 1.9 & 2.0 & 2.4 & 3.5 \\
\hline So sad nothing can cheer up & 1.2 & 1.2 & 2.1 & 1.8 & 2.5 & 3.4 \\
\hline Restless and fidgety & 2.4 & 2.7 & 3.9 & 3.8 & 4.2 & 5.5 \\
\hline Nervous & 4.2 & 4.5 & 6.3 & 6.7 & 7.7 & 9.4 \\
\hline Everything was an effort & 26.9 & 31.8 & 38.3 & 22.4 & 25.3 & 29.4 \\
\hline \multicolumn{7}{|c|}{ Overall K-6 psychological distress (a maximum of 24) } \\
\hline High psychological distress (score $\geq 13$ ) & 4.2 & 4.8 & 6.2 & 5.7 & 7.3 & 8.5 \\
\hline
\end{tabular}

Our findings provide evidence on age and sex differences in both psychological distress and mental health of caregivers. Previous literature has also reported that women positioned themselves as natural caregivers and they did not find caregiving as rewarding as male caregivers (Ekwall and Hallberg 2007). Our results are supportive of this conclusion. Our results also confirmed previous literature on the association between lower psychological distress

Table 3 Thai Mental Health Indicator and caregiver status by sex, Thai Cohort Study 2009

\begin{tabular}{|c|c|c|c|c|c|c|}
\hline \multirow{3}{*}{$\begin{array}{l}\text { Thai Mental Health Indicator } \\
N=60,569\end{array}$} & \multicolumn{6}{|c|}{ Column (\%) by caregiver status } \\
\hline & \multicolumn{3}{|c|}{ Males } & \multicolumn{3}{|c|}{ Females } \\
\hline & Non & Part-time & Full-time & Non & Part-time & Full-time \\
\hline \multicolumn{7}{|l|}{ Mental state (reported 'very much') } \\
\hline \multicolumn{7}{|l|}{ Positive effect } \\
\hline Self-esteem & 27.2 & 28.6 & 34.7 & 27.0 & 27.3 & 34.3 \\
\hline Content with life & 13.3 & 13.5 & 18.3 & 10.6 & 10.5 & 12.8 \\
\hline Relaxed & 7.7 & 6.8 & 8.8 & 6.7 & 6.2 & 7.5 \\
\hline \multicolumn{7}{|l|}{ Negative effect } \\
\hline Bored and discouraged with life & 31.5 & 28.4 & 32.3 & 24.3 & 21.5 & 23.2 \\
\hline Disappointed in myself & 46.2 & 40.7 & 42.9 & 49.9 & 45.9 & 49.6 \\
\hline Life is full of miseries & 50.4 & 43.7 & 42.6 & 52.6 & 45.8 & 45.4 \\
\hline \multicolumn{7}{|l|}{ Mental capacity (reported 'very much') } \\
\hline Can face and accept problems & 11.8 & 10.9 & 11.7 & 10.3 & 10.3 & 12.6 \\
\hline Can control emotions in crisis & 12.8 & 12.4 & 15.0 & 8.1 & 8.5 & 11.0 \\
\hline Confident in facing crises & 14.8 & 15.6 & 16.4 & 8.7 & 9.9 & 12.5 \\
\hline \multicolumn{7}{|l|}{ Mental quality (reported 'very much') } \\
\hline Sympathetic towards others & 22.8 & 23.3 & 27.4 & 25.8 & 26.3 & 31.6 \\
\hline Help others when have a chance & 24.7 & 25.7 & 28.6 & 28.4 & 30.6 & 37.3 \\
\hline Happy in helping out others & 37.1 & 38.1 & 41.6 & 39.4 & 41.5 & 45.8 \\
\hline \multicolumn{7}{|l|}{ Social support (reported 'very much') } \\
\hline Feel secured when stay with my family & 44.1 & 42.2 & 47.4 & 53.4 & 51.2 & 52.5 \\
\hline Trust family will take care of me when ill & 46.7 & 44.9 & 47.7 & 51.7 & 48.0 & 49.1 \\
\hline Family members love and care for each other & 47.8 & 45.5 & 52.1 & 50.6 & 46.5 & 50.3 \\
\hline
\end{tabular}


Table 4 High psychological distress, caregiver status and other covariates, Thai Cohort Study 2009

\begin{tabular}{lcr}
\hline $\begin{array}{l}\text { Cohort characteristics } \\
\mathbf{N}=\mathbf{6 0 , 5 6 9}\end{array}$ & \multicolumn{2}{c}{$\begin{array}{c}\text { High psychological distress (Kessler-6)* Adjusted } \\
\text { Multivariate Odds Ratios [95\% Confidence Interv }\end{array}$} \\
\cline { 2 - 3 } Caregiver status & Males & Females \\
Non caregiver & reference & reference \\
Part-time caregiver & $\mathbf{1 . 3 3}[1.20-1.49]$ & $\mathbf{1 . 3 2}[1.20-1.44]$ \\
Full-time caregiver & $\mathbf{1 . 7 8}[1.49-2.13]$ & $\mathbf{1 . 4 5}[1.24-1.70]$
\end{tabular}

\section{Demographic characteristics}

$$
\begin{aligned}
& \text { 20-29 } \\
& 30-39 \\
& 40+
\end{aligned}
$$

Age (year)

Marital status

Married

Never married

Separated, divorced, widowed

\section{Socio-geographic characteristics}

Household monthly income (Baht)

$$
\begin{aligned}
& <10,000 \\
& 10,000-19,999 \\
& 20,000-30,000 \\
& >30,000
\end{aligned}
$$

Wok status

Doing paid work

Unpaid family workers

Seeking work

Others

Geographical residence

Rural residence

Urban residence

\section{Health-risk behaviours}

$$
\begin{aligned}
& \text { Regular smokers - yes } \\
& \text { Regular smokers - no } \\
& \text { Regular alcohol drinkers - yes } \\
& \text { Regular alcohol drinkers - no }
\end{aligned}
$$

\section{Social contacts}

$$
\begin{aligned}
& \text { Colleagues - every week } \\
& \text { Colleagues - once or twice per month } \\
& \text { Colleagues - rarely or never } \\
& \text { Neighbours - every week } \\
& \text { Neighbours - once or twice per month } \\
& \text { Neighbours - rarely or never } \\
& \text { Friends - every week } \\
& \text { Friends - once or twice per month } \\
& \text { Friends - rarely or never }
\end{aligned}
$$

$$
\begin{aligned}
& 1.62[1.42-1.86] \\
& \mathbf{1 . 3 9}[1.23-1.57]
\end{aligned}
$$$$
\text { reference }
$$

reference

1.21 [1.10-1.32]

1.79 [1.55-2.07]

$$
\begin{aligned}
& \mathbf{2 . 2 6}[1.89-2.70] \\
& \mathbf{1 . 7 3}[1.46-2.05] \\
& \mathbf{1 . 2 0}[1.03-1.39] \\
& \text { reference }
\end{aligned}
$$$$
\text { reference }
$$$$
1.21 \text { [0.98-1.49] }
$$$$
2.00 \text { [1.54-2.60] }
$$$$
1.10 \text { [0.97-1.26] }
$$

reference

1.02 [0.92-1.13]
1.44 [1.28-1.63] reference

1.35 [1.20-1.52]

reference

reference

1.12 [0.96-1.30]

1.36 [1.19-1.95]

reference

0.98 [1.19-1.95]

0.99 [1.19-1.95]

reference

0.96 [1.19-1.95]

1.27 [1.10-1.47]
1.91 [162-2.23]

1.56 [1.34-1.80]

$1.31[1.14-1.51]$ reference

reference

1.06 [0.91-1.23]

$1.94[1.53-2.46]$

1.09 [0.96-1.34]

reference

1.10 [1.01-1.20]

1.86 [1.21-2.84] reference

1.32 [1.13-1.55]

reference

reference 1.03 [0.89-1.20]

1.33 [1.19-1.49]

1.11 [0.91-1.36]

1.04 [0.91-1.19]

1.10 [0.92-1.31]

1.42 [1.24-1.63]

*Those whose total score was $\geq 13$ out of a maximum of 24 were classified as having high psychological distress. 
and advancing age; a longitudinal analysis in the USA spanning more than 20 years showed that adults reported fewer negative emotions as they grew older (Charles et al. 2001). Hence younger caregivers are more likely to be at risk of adverse mental health.

Our findings provide strong evidence that lack of social contacts with friends and colleagues contributes to psychological distress. Other Thai studies found social support is important for both caregivers and care recipients and can reduce depression among impaired Thai older adults (Suttajit et al. 2010; Thanakwang 2009). In addition, social support could help to provide respite care and leisure time enabling the caring role to be sustained (Stevens et al. 2004; van Exel et al. 2008). These points reveal the important but complex role that social networks can play in assisting caregivers and enhancing access social support should be further examined.

The importance of religion and spiritual wellbeing among caregivers has been examined internationally (Hebert et al. 2006; Leblanc et al. 2004; Yeh and Bull 2009). In Thailand, Buddhist concepts are viewed by many as part of daily life and this also applies to Thai caregivers. A qualitative study in Thailand has supported the Buddhist view highlighting caregivers' suffering, acceptance and compassion (Sethabouppha and Kane 2005). Thai cohort members overall have strongly affirmed the importance of karma and religion in their daily lives (Yiengprugsawan et al. 2010).

The strength of this study is its large national scale and its wide array of sociodemographic and health covariates. One of the limitations of this current analysis is the cross-sectional data which does not permit causal interpretation; however subsequent cohort follow-up will permit longitudinal analyses. In addition, we note that the questionnaire was self-administered; however, cohort members were university educated which should facilitate the understanding of the questions. Further in-depth study on the nature, intensity, and burden of caregiving among Thai cohort members will provide insights into the long term outcomes which could provide vital information on the social and health support required for caregivers.

This study underlines the importance and prevalence of caregivers in Thailand, the strong possibility of mental health benefits, some risks of associated psychological distress, and the positive role of keeping social contacts. One of the main differences to be expected in lower income nations than that previously observed in higher income nations that formal social welfare support measures for caregivers are yet to be implemented. This study highlights the alarming need for such support. Early identification of vulnerable caregivers is required to target effective health promotion.

Abbreviations

TCS: Thai Cohort Study; STOU: Sukhothai Thammathirat Open University; TMHI: Thai Mental Health Indicators; AOR: Adjusted Odds Ratios.

Competing interests

The authors declare that they have no competing interests.

Authors' contributions

VY analysed data and drafted the manuscript. AS and SS devised and directed the Thai Cohort Study (TCS) and provided comments on the draft. All authors approved the final manuscript submission. 
Friel, David Harley, Matthew Kelly, Tord Kjellstrom, Lynette Lim, Roderick McClure, Anthony McMichael, Tanya Mark, Adrian Sleigh, Lyndall Strazdins, Vasoontara Yiengprugsawan.

\section{Acknowledgments}

This study was supported by the International Collaborative Research Grants Scheme with joint grants from the Wellcome Trust UK (GR071587MA) and the Australian National Health and Medical Research Council (NHMRC 268055), and as a global health grant from the NHMRC (585426). We thank the staff at Sukhothai Thammathirat Open University (STOU) who assisted with student contact and the STOU students who are participating in the cohort study. We also thank Dr Bandit Thinkamrop and his team from Khon Kaen University for guiding us successfully through the complex data processing. We thank the editor and reviewers for their comments and Matthew Kelly for editorial support to improve the manuscript.

\section{Author details}

${ }^{1}$ National Centre for Epidemiology and Population Health, The Australian National University, Canberra, Australia.

${ }^{2}$ School of Human Ecology, Sukhothai Thammathirat Open University, Nonthaburi, Thailand.

Received: 25 January 2012 Accepted: 10 August 2012

Published: 16 August 2012

\section{References}

Baronet, A. M. (2003). The impact of family relations on caregivers' positive and negative appraisal of their caretaking activities. Family Relations, 52(2), 137-142.

Brouwer, W. B. F., van Exel, N. J. A., van den Berg, B., van den Bos, G. A. M., \& Koopmanschap, M. A. (2005). Process utility from providing informal care: the benefit of caring. Health Policy, 74(1), 85-99.

Brown, E. (2007). Care recipients' psychological well-being: the role of sense of control and caregiver type. Aging Ment Health, 11(4), 405-414.

Chang, B. L., Brecht, M. L., \& Carter, P. A. (2001). Predictors of social support and caregiver outcomes. Women Health, 33(1-2), 39-61.

Charles, S. T., Reynolds, C. A., \& Gatz, M. (2001). Age-related differences and change in positive and negative affect over 23 years. J Pers Soc Psychol, 80(1), 136-151.

Chou, Y. C., Fu, L. Y., Kroger, T., \& Ru-Yan, C. (2010). Job satisfaction and quality of life among home care workers: a comparison of home care workers who are and who are not informal carers. Int Psychogeriatr, 16, 1-12.

Cohen, C. A., Colantonio, A., \& Vernich, L. (2002). Positive aspects of caregiving: rounding out the caregiver experience. Int J Geriatr Psychiatry, 17(2), 184-188.

Ekwall, A. K., \& Hallberg, I. R. (2007). The association between caregiving satisfaction, difficulties and coping among older family caregivers. Journal of Clinical Nursing, 16(5), 832-844.

Fushimi, M., Saito, S., Shimizu, T., Kudo, Y., Seki, M., \& Murata, K. (2011). Prevalence of psychological distress, as measured by the Kessler 6 (K6), and related factors in Japanese employees. Community Ment Health J. doi:10.1007/s10597-011-9416-7.

Godfrey, J. R., \& Warshaw, G. A. (2009). Toward optimal health: considering the enhanced healthcare needs of women caregivers. J Womens Health (Larchmt), 18(11), 1739-1742.

Guerra, S., Vicente, H., Figueiredo, D., \& Sousa, L. (2008). Informal caregivers of elderly people: social network and life satisfaction. International Journal of Psychology, 43(3-4), 273-273.

Hebert, R. S., Weinstein, E., Martire, L. M., \& Schulz, R. (2006). Religion, spirituality and the well-being of informal caregivers: a review, critique, and research prospectus. Aging Ment Health, 10(5), 497-520.

Ho, S. C., Chan, A., Woo, J., Chong, P., \& Sham, A. (2009). Impact of caregiving on health and quality of life: a comparative population-based study of caregivers for elderly persons and noncaregivers. J Gerontol A Biol Sci Med Sci, 64(8), 873-879.

Hozawa, A., Kuriyama, S., Nakaya, N., Ohmori-Matsuda, K., Kakizaki, M., Sone, T., et al. (2009). Green tea consumption is associated with lower psychological distress in a general population: the Ohsaki Cohort 2006 Study. Am J Clin Nutr, 90(5), 1390-1396.

Hussein, S., \& Manthorpe, J. (2005). An international review of the long-term care workforce: policies and shortages. J Aging Soc Policy, 17(4), 75-94.

Kessler, R. C., Barker, P. R., Colpe, L. J., Epstein, J. F., Gfroerer, J. C., Hiripi, E., et al. (2003). Screening for serious mental illness in the general population. Arch Gen Psychiatry, 60(2), 184-189.

Koerner, S. S., Kenyon, D. B., \& Shirai, Y. (2009). Caregiving for elder relatives: Which caregivers experience personal benefits/gains? Archives of Gerontology and Geriatrics, 48(2), 238-245.

Kong, E. H. (2007). The influence of culture on the experiences of Korean, Korean American, and Caucasian-American family caregivers of frail older adults: a literature review. Taehan Kanho Hakhoe Chi, 37(2), 213-220.

Kuuppelomaki, M., Sasaki, A., Yamada, K., Asakawa, N., \& Shimanouchi, S. (2004). Family carers for older relatives: sources of satisfaction and related factors in Finland. Int J Nurs Stud, 41(5), 497-505.

Leblanc, A. J., Driscoll, A. K., \& Pearlin, L. I. (2004). Religiosity and the expansion of caregiver stress. Aging Ment Health, 8(5), 410-421.

Mongkol, A., Tangseree, T., Udomratn, P., Huttapanom, W., \& Chuta, W. (2007). The development of Thai Mental Health Indicator (TMHI): from past to present. The 3rd International Conference on Gross National Happiness Towards Global Transformation. Thailand: Ministry of Public Health.

Mongkol, A., Huttapanom, W., Chetchotisakd, P., Chalookul, W., Punyoyai, L., \& Suvanashiep, S. (2001). The study to develop Thai Mental Health Indicator. J Psychiatr Assoc Thailand, 46(3), 209-225.

Ribeiro, O., \& Paul, C. (2008). Older male carers and the positive aspects of care. Ageing \& Society, 28, 165-183.

Savage, S., \& Bailey, S. (2004). The impact of caring on caregivers' mental health: a review of the literature. Aust Health Rev, 27(1), 111-117. 
Sethabouppha, H., \& Kane, C. (2005). Caring for the seriously mentally ill in Thailand: Buddhist family caregiving. Arch Psychiatr Nurs, 19(2), 44-57.

Shirai, Y., Koerner, S. S., \& Kenyon, D. B. (2009). Reaping caregiver feelings of gain: The roles of socio-emotional support and mastery. Aging \& Mental Health, 13(1), 106-117.

Singleton, J. (2000). Women caring for elderly family members: Shaping non-traditional work and family initiatives. J Comp Fam Stud, 31(3), 367

Sinokki, M., Hinkka, K., Ahola, K., Koskinen, S., Kivimaki, M., Honkonen, T., et al. (2009). The association of social support at work and in private life with mental health and antidepressant use: the Health 2000 Study. J Affect Disord, $115(1-2), 36-45$

Sleigh, A. C., Seubsman, S. A., \& Bain, C. (2008). Cohort profile: The Thai Cohort of 87,134 Open University students. Int J Epidemiol, 37(2), 266-272.

Songprakun, W., \& McCann, T. V. (2012). Evaluation of a cognitive behavioural self-help manual for reducing depression: a randomized controlled trial. J Psychiatr Ment Health Nurs. doi:10.1111/j.1365-2850.2011.01861.x.

Stevens, A. B., Coon, D., Wisniewski, S., Vance, D., Arguelles, S., Belle, S., et al. (2004). Measurement of leisure time satisfaction in family caregivers. Aging \& Mental Health, 8(5), 450-459.

Stoltz, P., Uden, G., \& Willman, A. (2004). Support for family carers who care for an elderly person at home - a systematic literature review. Scand J Caring Sci, 18(2), 111-119.

Suttajit, S., Punpuing, S., Jirapramukpitak, T., Tangchonlatip, K., Darawuttimaprakorn, N., Stewart, R., et al. (2010). Impairment, disability, social support and depression among older parents in rural Thailand. Psychol Med, 40(10), $1711-1721$.

Tawatsupa, B., Lim, L. L.-Y., Kjellstrom, T., Seubsman, S., Sleigh, A., \& Team, T. T. C. S. (2010). The association between overall health, psychological distress, and occupational heat stress among a large national cohort of 40,913 Thai workers. Global Health Action. doi:10.3402/gha.v3i0.5034.

Thanakwang, K. (2009). Social relationships influencing positive perceived health among Thai older persons: a secondary data analysis using the National Elderly Survey. Nurs Health Sci, 11(2), 144-149.

Treasure, J. (2004). Review: exploration of psychological and physical health differences between caregivers and noncaregivers. Evid Based Ment Health, 7(1), 28.

Ussher, J. M., \& Perz, J. (2010). Gender differences in self-silencing and psychological distress in informal cancer carers. Psychol Women Quart, 34(2), 228-242.

van Exel, J., de Graaf, G., \& Brouwer, W. (2008). Give me a break! Informal caregiver attitudes towards respite care. Health Policy, 88(1), 73-87.

Vitaliano, P. P., Zhang, J., \& Scanlan, J. M. (2003). Is caregiving hazardous to one's physical health? A meta-analysis. Psychol Bull, 129(6), 946-972.

Yamamoto-Mitani, N., Ishigaki, K., Kuniyoshi, M., Kawahara-Maekawa, N., Hayashi, K., Hasegawa, K., et al. (2004). Subjective quality of life and positive appraisal of care among Japanese family caregivers of older adults. Qual Life Res, 13(1), 207-221.

Yeh, P. M., \& Bull, M. (2009). Influences of spiritual well-being and coping on mental health of family caregivers for elders. Res Gerontol Nurs, 2(3), 173-181.

Yiengprugsawan, V., Seubsman, S., \& Sleigh, A. C. (2010). Health, well-being, and social indicators among monks, prisoners, and other adult members of an open university cohort in Thailand. J Relig Health. doi:10.1007/s10943-010-9410-3.

Yiengprugsawan, V., Khamman, S., Seubsman, S. A., Lim, L. L., \& Sleigh, A. C. (2011). Social capital and health in a national cohort of 82,482 Open University adults in Thailand. J Health Psychol, 16(4), 632-642.

Yiengprugsawan, V., Somboonsook, B., Seubsman, S., \& Sleigh, A. C. (2011). Happiness, mental health, and socio-demographic associations among a national cohort of Thai adults. J Happiness Stud, doi:10.1007/s10902-10011-19304-10904.

doi:10.1186/2211-1522-2-4

Cite this article as: Yiengprugsawan et al:: Psychological distress and mental health of Thai caregivers. Psychology of Well-Being: Theory, Research and Practice 2012 2:4.

\section{Submit your manuscript to a SpringerOpen ${ }^{\circ}$} journal and benefit from:

- Convenient online submission

Rigorous peer review

- Immediate publication on acceptance

- Open access: articles freely available online

- High visibility within the field

- Retaining the copyright to your article

Submit your next manuscript at $\boldsymbol{\sim}$ springeropen.com 